\title{
Buchtipp
}

\section{Ratgeber für Betroffene und Angehörige}

Der Hauptverband der österreichischen Sozialversicherungsträger klärt in einem neuen Buch über Rheuma auf.

Der Ratgeber „Rheuma - Das Chamäleon unter den Krankheiten" ist bereits der 7. Band aus der Serie "Gesund werden. Gesund bleiben". Erhältlich ist das Buch im Buchhandel zum Preis von 24,90 Euro oder kostenfrei über den Hauptverband der österreichischen Sozialversicherungsträger (www.hauptverband.at/ Onlineshop).

Der Hauptverband der österreichischen Sozialversicherungsträger will mit dem neuen Ratgeber über Rheuma aufklären, Symptome erklären und Betroffene und Angehörige sensibilisieren. „Rheuma ist eine Krankheit mit

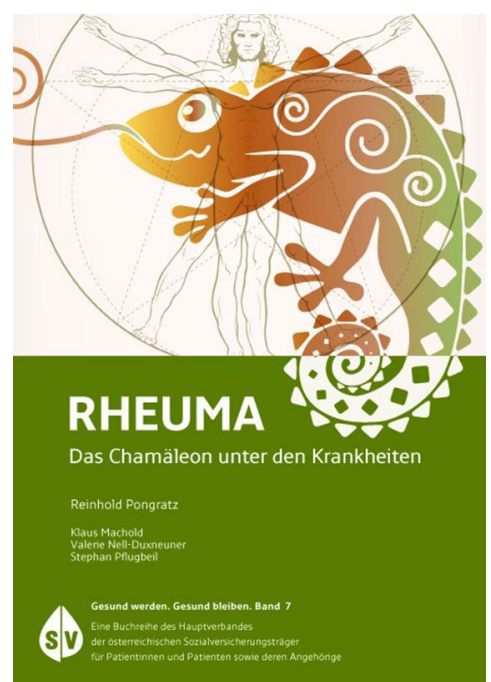

vielen Gesichtern. Nur wer auf seine Patienten eingeht und innen zuhört, wird die richtige Therapie finden", so Prof. Dr. Klaus Machold, Rheumatologe und Präsident der Österreichischen Gesellschaft für Rheumatologie und Rehabilitation und Co-Autor des Ratgebers.

rheuma plus $2016 \cdot 15: 93$

DOI 10.1007/s12688-016-0095-x

Online publiziert: 24. Oktober 2016

o) Springer-Verlag Wien 2016

Hier steht eine Anzeige. 